\title{
Hospital-Acquired Pneumonia: The Lebanese Societies for Pulmonary, Critical Care, and Infectious Diseases and Clinical Microbiology Joint Guidelines
}

\section{Moussa Riachy}

Saint Joseph University Medical School, Hôtel-Dieu de France Hospital, Beirut

Aline El Zakhem

American University of Beirut Medical Center, Beirut

Claude Afif

Saint George Hospital University Medical Center, Beirut

Jacques Choucair

Saint Joseph University Medical School, Hôtel-Dieu de France Hospital, Beirut

\section{Patricia Yazbeck}

Saint Joseph University Medical School, Hôtel-Dieu de France Hospital, Beirut

\section{Madonna J. Matar}

The Holy Spirit University of Kaslik, School of Medicine and Medical Sciences, Notre-Dame de Secours University Hospital, Jbeil

\section{Zeina Aoun-Bacha}

Saint Joseph University Medical School, Hôtel-Dieu de France Hospital, Beirut

\section{Wajdy Abi Saleh}

Clemenceau Medical Center, Beirut

\section{Georges S. Juvelekian}

Saint George Hospital University Medical Center, Beirut

\section{Nadine Yared}

Mount Lebanon Hospital-Balamand University Medical Center, Beirut

\section{Pierre Bou Khalil}

American University of Beirut Medical Center, Beirut

\section{Viviane Chalhoub}

Saint Joseph University Medical School, Hôtel-Dieu de France Hospital, Beirut

\section{Ralph Nehme}

Lebanese American University Medical Center-Rizk Hospital, Beirut

\section{Youssef Haddad}

Lebanese University, Lebanese Hospital, Beirut

\section{Salah Zeineldine}


American University of Beirut Medical Center, Beirut

\section{Rani Abu Khuzam}

Ain w Zain Hospital, Ain W Zain

Souha S. Kanj ( $\sim$ sk11@aub.edu.lb)

American University of Beirut Medical Center, Beirut

\section{Research Article}

Keywords: antibiotics, guidelines, hospital-acquired pneumonia, intensive care unit, Lebanon, mechanical ventilation, nosocomial pneumonia, ventilator-associated pneumonia

Posted Date: May 3rd, 2021

DOI: https://doi.org/10.21203/rs.3.rs-398183/v1

License: (c) (i) This work is licensed under a Creative Commons Attribution 4.0 International License. Read Full License 
1 Hospital-Acquired Pneumonia: The Lebanese Societies for Pulmonary, Critical Care, and

2 Infectious Diseases and Clinical Microbiology Joint Guidelines

$4 \quad$ Moussa Riachy, $\mathrm{MD}^{1}$; Aline El Zakhem, $\mathrm{MD}^{2}$; Claude Afif, $\mathrm{MD}^{3}$; Jacques Choucair, $\mathrm{MD}^{4}$;

5 Patricia Yazbeck, MD ${ }^{5}$; Madonna J. Matar, MD, MPH ${ }^{6}$; Zeina Aoun-Bacha, MD ${ }^{7}$; Wajdy Abi

6 Saleh, $\mathrm{MD}^{8}$; Georges S. Juvelekian, $\mathrm{MD}^{9}$; Nadine Yared, $\mathrm{MD}, \mathrm{MPH}^{10}$; Pierre Bou Khalil,

$7 \quad \mathrm{MD}^{11}$; Viviane Chalhoub, $\mathrm{MD}^{12}$; Ralph Nehme, $\mathrm{MD}^{13}$; Youssef Haddad, $\mathrm{MD}^{14}$; Salah

8 Zeineldine, $\mathrm{MD}^{15}$; Rani Abu Khuzam, MD, EMHCL ${ }^{16}$; and Souha S. Kanj, $\mathrm{MD}^{17^{*}}$

1 Saint Joseph University Medical School, Hôtel-Dieu de France Hospital, Beirut, Lebanon.

11 Email: moussa.riachy@hdf.usj.edu.lb

122 American University of Beirut Medical Center, Beirut, Lebanon. Email: az51@aub.edu.lb

133 Saint George Hospital University Medical Center, Beirut, Lebanon. Email:

14 cmafif@stgeorgehospital.org

154 Saint Joseph University Medical School, Hôtel-Dieu de France Hospital, Beirut, Lebanon.

$16 \quad$ Email: jacques.choucair@hdf.usj.edu.lb

175 Saint Joseph University Medical School, Hôtel-Dieu de France Hospital, Beirut, Lebanon.

18 Email: patricia.yazbeck@hdf.usj.edu.lb

196 The Holy Spirit University of Kaslik, School of Medicine and Medical Sciences, Notre-Dame

20 de Secours University Hospital, Jbeil, Lebanon. Email: madonnamatar@usek.edu.lb

217 Saint Joseph University Medical School, Hôtel-Dieu de France Hospital, Beirut, Lebanon.

22 Email: zeina.aoun@hdf.usj.edu.lb

238 Clemenceau Medical Center, Beirut, Lebanon. Email: wajdy.abisaleh@cmc.com.lb 
249 Saint George Hospital University Medical Center, Beirut, Lebanon. Email:

25 gsjuvelekian@ stgeorgehospital.org

2610 Mount Lebanon Hospital-Balamand University Medical Center, Beirut, Lebanon. Email:

27 nadine.yared@ fty.balamand.edu.lb

2811 American University of Beirut Medical Center, Beirut, Lebanon. Email: pb05@aub.edu.lb

2912 Saint Joseph University Medical School, Hôtel-Dieu de France Hospital, Beirut, Lebanon.

$30 \quad$ Email: viviane.chalhoub@usj.edu.lb

31 13 Lebanese American University Medical Center-Rizk Hospital, Beirut, Lebanon. Email:

32 ralph.nehme@laumcrh.com

33 14 Lebanese University, Lebanese Hospital, Beirut, Lebanon. Email: youcef.haddad@ul.edu.lb

3415 American University of Beirut Medical Center, Beirut, Lebanon. Email: sz01 @ aub.edu.lb

3516 Ain w Zain Hospital, Beirut, Lebanon. Email: raniabukhuzam@ awmedicalvillage.org

3617 American University of Beirut Medical Center, Beirut, Lebanon. Email: sk11@aub.edu.lb;

$37 \quad$ souha.s.kanj@gmail.com

39 *Corresponding author: Dr. Souha S. Kanj, MD. Department of Internal Medicine, Division of

40 Infectious Diseases, American University of Beirut Medical Center, Beirut, Lebanon. Postal

41 address: American University of Beirut Medical Center, Riad El Solh, PO Box 11-0236, Beirut,

421107 2020, Lebanon.; email: sk11@aub.edu.lb; souha.s.kanj@gmail.com

44 Abstract

45 Background: The Lebanese Society of Infectious Diseases and Clinical Microbiology

46 (LSIDCM), the Lebanese Society of Critical Care Medicine (LSCCM), and the Lebanese 
47 Pulmonary Society (LPS) play a major role in guiding clinicians across Lebanon in prescribing 48 antibiotics for the management of hospital-acquired pneumonia (HAP) and ventilator-associated 49 pneumonia (VAP). Members of these societies have tailored the international recommendations 50 for the management of HAP/VAP to local epidemiological and microbiological data. The aims of 51 these local guidelines are to guide clinicians in the prevention of VAP, selection of appropriate 52 empiric and targeted antimicrobial regimens for VAP/HAP and to contribute to improving 53 patient outcomes.

54 Methods: Recommendations in these guidelines are adapted from international guidelines and 55 are modeled based on locally-derived epidemiological and microbiological data, as well as the 56 availability of antimicrobial agents and other resources.

57 Results: These guidelines aim to combine both clinical and bacteriological strategies to 58 appropriately diagnose and manage HAP/VAP. They recommend implementing evidence-based 59 preventive measures to lower the rate of VAP and improve patient outcomes. The recommended 60 duration of treatment with antibiotics in general should not exceed 7 days in patients with HAP 61 whereas it should be 7-8 days in patients with VAP. Imunnosuppressed patients with 62 Pseudomonas aeruginosa infection might require longer courses. Ceftolozane/tazobactam 63 (CFT/TAZ) and ceftazidime/avibactam (CAZ/AVI) are considered good options in patients with 64 HAP/VAP caused by extended spectrum beta-lactamase-producing Enterobacterales and multidrug-resistant Pseudomonas aeruginosa. They also play a key role in the implementation of a carbapenem-sparing strategy in an antimicrobial stewardship program.

67 Conclusion: These guidelines represent a major step towards establishing Lebanese national guidelines for the management of HAP/VAP. They also emphasize on timeliness and appropriateness of antibiotic therapy for the management of HAP/VAP. 
71 Keywords: antibiotics; guidelines; hospital-acquired pneumonia; intensive care unit; Lebanon;

72 mechanical ventilation; nosocomial pneumonia; ventilator-associated pneumonia

73

74

75

76

77

78

79

80

81

82

83

84

85

86

87

88

89

90

91

92

\section{Background}

Nosocomial pneumonia (NP) is the most common nosocomial infection observed among patients in the intensive care unit (ICU). NP includes hospital-acquired pneumonia (HAP) and ventilatorassociated pneumonia (VAP) which are associated with life-threatening complications and increased morbidity and mortality (1).

Different rates of HAP/VAP have been reported from varying regions around the world. In 2013, the National Healthcare Safety Network (NHSN) reported that the average rate of VAP in the United States of America (USA) was 1-2.5 cases/1000 days of mechanical ventilation (MV) (2). A recent study from the USA revealed a rate of HAP of $1.6 \%$ in hospitalized patients (3). The European Center for Disease Prevention and Control (ECDC) described that the rate of VAP was 8.9 episodes/1000 days of MV (4), and the prevalence of HAP was 1.3\% (5). In the Middle East, a multicenter study by the Gulf Cooperation Council reported a VAP rate of 4.8 per 1000 ventilator days according to data collected from Oman, Bahrain, and Saudi Arabia (6). Recently, a study from a tertiary care center in Lebanon over a 10-year period reported a VAP rate of 7.9 per 1000 ventilator-days and examined the causative bacterial pathogens (7).

Mortality has been reported to be significantly increased in patients with HAP. Micek et al. (8) reported that patients with HAP have an 8.4-fold increased risk of death, an 8-fold increase in need for MV, and a longer duration of hospitalization compared with patients without HAP. Among 
93 ICU patients, crude mortality of HAP and VAP was the same (9). Recently, an analysis of seven 94 clinical trial datasets showed that ICU patients with ventilated-HAP (vHAP) had the highest all95 cause mortality rate at day $28(27.8 \%)$, followed by VAP (18\%) and non-ventilated HAP (NV96 HAP) (14.5\%) (10).

97 HAP has been associated with serious complications including respiratory failure, pleural 98 effusions, septic shock, renal failure, and empyema (1). In addition, studies estimated that VAP 99 prolongs the length of MV by 7.6 to 11.5 days and hospitalization by 11.5 to 13.1 days compared 100 to similar patients without VAP $(11,12)$. Moreover, HAP/VAP cause an increased cost of care and 101 considerable financial burden where the excess cost was estimated to be approximately $\$ 40,000$ 102 per patient $(3,12)$.

103 The NHSN data reports from 2016 showed that Staphylococcus aureus (24.7\%) was the most 104 prevalent pathogen causing VAP in the USA followed by Pseudomonas aeruginosa (16.5\%) (13). 105 A study that assessed the microbiological etiologies of HAP/VAP in USA, Europe, and Latin 106 America found that the incidence of pathogens causing HAP/VAP was consistent over more than 10710 years with the 6 most prevalent pathogens being S. aureus (28\%), P. aeruginosa (21.8\%), 108 Klebsiella species (9.8\%), Escherichia coli (6.9\%), Acinetobacter species (6.3\%), and 109 Enterobacter species (6.8\%). These pathogens were responsible for around 80\% of HAP or VAP 110 episodes; P. aeruginosa and Acinetobacter species were more common in VAP cases (14).

111 Data on HAP/VAP epidemiology, microbiology, and susceptibility of causative organisms from 112 the Arab countries in the Middle East are scarce. Table 1 summarizes the findings of 3 studies 113 from Lebanon. In a 10-year study from Lebanon, S. aureus, P. aeruginosa, Klebsiella species, E. 114 coli, Acinetobacter species, and Enterobacter species were the most common pathogens 115 associated with VAP (7). Despite being comparable to data from western countries, such data 
116 might not be representative on the national level and variation from one institution to another is

117 possible. A recent report proposed a VAP treatment algorithm based on international guidelines

118 and tailored to local hospital microbiology (15).

119 HAP/VAP are associated with multidrug-resistant organisms (MDROs) leading to poor outcomes.

120 Susceptibility data in pathogens isolated from VAP cases showed extensively and multidrug-

121 resistant (MDR) pathogens, including Acinetobacter species and P. aeruginosa, to be prevalent

$122(7,16)$.

123

124 Table 1. Distribution of bacteria causing VAP according to local studies

\begin{tabular}{|c|c|c|c|}
\hline Organism & $\begin{array}{l}\text { Kanafani et al. } \\
\qquad 2003(16)\end{array}$ & $\begin{array}{l}\text { Awad et al. } \\
2018 \text { (15) }\end{array}$ & $\begin{array}{c}\text { Kanafani et al. } \\
2019(7)\end{array}$ \\
\hline Acinetobacter baumannii & - & $37.33 \%$ & $32.6 \%$ \\
\hline Acinetobacter anitratus & $24 \%$ & - & - \\
\hline Pseudomonas aeruginosa & $17.4 \%$ & $30.67 \%$ & $16.5 \%$ \\
\hline Enterobacterales & - & $14.67 \%$ & - \\
\hline Klebsiella species & $13 \%$ & - & $8.3 \% *$ \\
\hline Escherichia coli & $10.9 \%$ & - & $12.4 \%$ \\
\hline Enterobacter species & $4.3 \%$ & - & $5 \%$ \\
\hline Stenotrophomonas maltophilia & $6.5 \%$ & $12 \%$ & $6 \%$ \\
\hline Coagulase-negative staphylococci & $10.9 \%$ & - & - \\
\hline Staphylococcus aureus & $6.5 \%$ & $4 \%$ & $4.6 \%$ \\
\hline Others & $6.5 \%$ & $1.33 \%$ & $3.7 \%$ \\
\hline Serratia marcescens & - & - & $3.7 \%$ \\
\hline
\end{tabular}




\begin{tabular}{|l|c|c|c|}
\hline Proteus mirabilis & - & - & $3.7 \%$ \\
\hline Citrobacter species & - & - & $2.3 \%$ \\
\hline Burkholderia cepacia & - & - & $1.4 \%$ \\
\hline
\end{tabular}

* Klebsiella pneumoniae

127 The extensive and random use of antibiotics, particularly broad-spectrum agents, imposes a 128 substantial financial burden on hospitals and national healthcare systems, and increases the risk of 129 emergence of MDROs. International recommendations for the management of HAP/VAP have to 130 be tailored to local epidemiological and microbiological data. Thus, establishing national 131 guidelines is essential to guide clinicians in the selection of appropriate empiric and targeted 132 antimicrobial regimens. In addition to implementing preventive bundles, these guidelines would 133 contribute to improving patient outcomes. These present guidelines were developed by a panel 134 including presidents and president elects of the 3 societies: the Lebanese Society of Infectious 135 Diseases and Clinical Microbiology (LSIDCM) (6 members), Lebanese Society of Critical Care 136 Medicine (LSCCM) (6 members), and the Lebanese Pulmonary Society (LPS) (5 members).

\section{Methods}

140 We reviewed the epidemiology of HAP/VAP worldwide and in Lebanon. Our recommendations

141 are adapted from international guidelines and are modeled based on locally-derived susceptibility

142 data and on the availability of various antimicrobial agents and other resources. These guidelines

143 describe detailed recommendations about diagnosis, prevention, and assessment of these 144 infections, identification of risk factors, and antimicrobial management in adults with HAP/VAP. 
145 Moreover, these guidelines describe the experience of two major Lebanese medical centers with 146 antimicrobial stewardship and the impact of COVID-19 and influenza viruses pandemics on the 147 clinical presentation and management of bacterial pneumonia. The international guidelines 148 reviewed herein are:

149 - The 2016 clinical practice guidelines of the Infectious Diseases Society of America and 150 the American Thoracic Society for the management of adults with hospital-acquired and 151 ventilator-associated pneumonia (1).

152 - The 2017 international guidelines of the European Respiratory Society (ERS), European 153 Society of Intensive Care Medicine (ESICM), European Society of Clinical Microbiology 154 and Infectious Diseases (ESCMID) and Asociación Latinoamericana del Tórax (ALAT) 155 for the management of HAP/VAP (20).

- The ESCMID guidelines for the management of the infection control measures to reduce transmission of multidrug-resistant Gram-negative bacteria in hospitalized patients (57).

- The clinical practice guidelines of the Association of Medical Microbiology and 159 Infectious Disease Canada and the Canadian Thoracic Society for HAP/VAP in adults (21).

- The joint guidelines of the Indian Chest Society (ICS) and the National College of Chest Physicians (NCCP) of India for diagnosis and management of community-acquired pneumonia (CAP) and HAP in adults (22). NP (33). 
- The guidelines of the American Thoracic Society and Infectious Diseases Society of America for the management of adults with HAP/VAP, and healthcare-associated pneumonia (63).

- The guidelines of the Spanish Society of Chemotherapy for antibiotic selection in the treatment of acute invasive infections by $P$. aeruginosa (79).

3. Results

\subsection{Definition of HAP/VAP}

HAP is a pneumonia that occurs 48 hours or more after admission which was not incubating at the time of admission and not associated with MV. VAP is a pneumonia that arises after more than 48 hours of MV. vHAP is a pneumonia that occurs 48 hours or more after admission which was not incubating at the time of admission and not associated with MV. It occurs in patients with severe HAP who require MV. ICU HAP is defined as a pneumonia that occurs 48 hours or more after ICU admission. Besides being associated with MDROs, vHAP has the highest mortality rate compared to VAP and non-ventilated HAP, a poor clinical prognosis, and the poorest clinical outcome $(17,18)$. Therefore, optimal antibiotic therapy should be selected and guided by local susceptibility rates and MDROs risk factors.

\subsection{Assessment and Diagnosis}

The clinical criteria for the diagnosis of VAP have a high sensitivity but a low specificity; critically ill ventilated patients can develop complications such as atelectasis, pulmonary edema, pulmonary 
190 embolism, and pulmonary trauma that may closely resemble VAP (19) and that need to be 191 considered in the differential diagnosis.

192 In addition to the clinical signs of respiratory infections (cough, sputum production, chest pain, 193 fever), the assessment of the patient should include:

194 - Radiological tests,

195 - Respiratory sample cultures,

196 - Analytical determinations,

197 - Scores from various rating scales such as the Clinical Pulmonary Infection Scale (CPIS) $198 \quad(20)$

199

$200 \quad 3.2 .1 \quad$ Clinical assessment

201 The diagnosis is usually made when a patient develops symptoms including fever, purulent 202 tracheobronchial secretions, and a new or changing pulmonary infiltrate or a new onset of 203 leukocytosis (21). Patients with a strong suspicion of VAP/HAP but insufficient evidence for 204 infection must be re-evaluated periodically (22). Risk stratification regarding the acquisition of 205 MDROs should be assessed to guide decisions on empiric antibiotic treatment (22).

206 A good practice in patients receiving antibiotherapy for VAP/HAP consists of doing a routine 207 bedside clinical assessment (20). This assessment consists of measuring body temperature, 208 performing a culture of the tracheobronchial secretion and assessing its purulence and volume, 209 evaluating the resolution of the chest radiograph infiltrate, evaluating white blood cell count and 210 arterial oxygen pressure/inspiratory oxygen fraction $\left(\mathrm{PaO}_{2} / \mathrm{FiO}_{2}\right)$, and calculating at least 1 of the 211 following scores: Acute Physiology and Chronic Health Evaluation II (APACHE II), CPIS, Organ 
212 Dysfunction and Infection System (ODIN), Simplified Acute Physiological Score II (SAPS II),

213 and Sequential Organ Failure Assessment (SOFA) (20).

214 Treatment is considered successful or the bacteria are eradicated in case of negative findings.

215 Negative findings can also suggest that the lung infection was not present initially, so antimicrobial

216 therapy should be adjusted or discontinued.

217 Several clinical factors of pneumonia can be evaluated semi-objectively using the CPIS (Table 2).

218 The clinical course of VAP can be described using serial CPIS measurements which allows the

219 identification of patients with a good therapeutic response 3 days after the diagnosis (23). A CPIS

220 of 0 to 6 is a low predictor of pneumonia whereas diagnosis is more certain when the score ranges

221 from 7 to 12. SOFA score is also used to assess HAP/VAP patients, wherein a decreased SOFA

222 score is associated with a decreased survival (24).

223

224 Table 2. Clinical Pulmonary Infection Scale

\begin{tabular}{|c|c|c|c|}
\hline CPIS & $\mathbf{0}$ & 1 & 2 \\
\hline Tracheal secretions & Rare & Abundant & $\begin{array}{l}\text { Abundant and } \\
\text { purulent }\end{array}$ \\
\hline $\begin{array}{l}\text { Chest X-ray } \\
\text { infiltrates }\end{array}$ & No infiltrate & Diffused & Localized \\
\hline Temperature $\left({ }^{\circ} \mathrm{C}\right)$ & $\geq 36.5$ and $\leq 38.4$ & $\geq 38.5$ and $\leq 38.9$ & $\geq 39$ and $\leq 36$ \\
\hline $\begin{array}{l}\text { Leukocytes count } \\
\text { (/mm3) }\end{array}$ & $\geq 4,000$ and $\leq 11,000$ & $<4,000$ and $>11,000$ & $\begin{array}{l}<4,000 \text { and }>11,000 \\
\text { and band forms } \geq 500\end{array}$ \\
\hline $\mathrm{PaO} 2 / \mathrm{FiO} 2(\mathrm{mmHg})$ & $\geq 240$ or ARDS & & $\begin{array}{l}\leq 240 \text { and no } \\
\text { evidence of ARDS }\end{array}$ \\
\hline
\end{tabular}




\begin{tabular}{|l|l|l|l|}
\hline Microbiology & Negative & & Positive \\
\hline
\end{tabular}

226 oxygen fraction. Adapted from Fartoukh M, et al., 2003 (25).

227

228 3.2.2 Microbiological assessment

229 In stable patients with suspected VAP/HAP, one or more lower respiratory tract samples should 230 be sent for Gram stain and culture before the initiation of antibiotics $(22,26)$, and a blood sample 231 should be sent for culture as well. A good quality sputum should be sent to the microbiology 232 laboratory in all patients suspected of having HAP $(>25$ leucocytes and $<10$ squamous cells per 233 low-power field). Semi-quantitative cultures of lower respiratory tract secretions can be performed 234 instead of qualitative cultures. They can be easier to interpret and equally discriminatory for the 235 presence of pneumonia as compared to quantitative cultures (22). In unstable patients, the 236 appropriate management should not be delayed to perform diagnostic sampling (22).

237 Lower respiratory tract samples (distal quantitative, proximal quantitative, qualitative) are 238 obtained to de-escalate and narrow the initial empiric antibiotic therapy (20).

$240 \quad 3.2 .3 \quad$ Radiological assessment

241 Chest X-rays are done routinely but are neither sensitive nor specific. CT scan should not be 242 routinely obtained for diagnosing HAP/VAP. 


\section{$244 \quad 3.2 .4$ Biological assessment}

245 No ideal biomarker for evaluating the therapeutic response is yet available. Theoretically, the main

246 characteristics of the ideal biomarker are affordability, easy access, timely manner results, and

247 contribution to decreasing the consumption of antibiotics (19).

248 The mid-regional pro-atrial natriuretic peptide, procalcitonin (PCT), C-reactive protein (CRP), and 249 copeptin have been suggested as biomarkers for NP $(19,20)$. However, treatment outcomes have 250 not yet been compared in HAP/VAP patients managed based on either the clinical assessment or 251 biomarker measurement (20).

252 PCT and CRP can help in monitoring and assessing prognosis where the measurement of PCT and 253 CRP at the beginning of VAP infection and on day 3-4 can predict mortality, and the decrease in 254 either one of these markers is a predictor of survival (24). The value of PCT particularly on day 3 255 highly predicts mortality risks (27).

256 An elevated level of PCT was found to be associated with an increased risk of mortality in critically 257 ill patients (28). The same meta-analysis showed that the prognostic performance of this biomarker 258 was almost the same in patients with VAP and those with CAP (28). Whether patients are to be 259 admitted to the ICU or treated as outpatients, the decision can be based on the additional 260 information provided by PCT for risk scores (28). Conversely, PCT has a limited role in cases of 261 hemodialysis, renal failure, and resuscitated cardiac arrest (29). The diagnosis of HAP/VAP (22), 262 or the decision to initiate or reduce the duration of treatment with antibiotics (30) cannot be made 263 based on PCT and CRP alone.

264 Since serial measurements of PCT levels have a marginal impact on shortening the duration of 265 antibiotic treatment in patients with a good response to initial treatment (20), relying on clinical 266 criteria is recommended to decide whether or not to initiate antibiotic treatment or follow-up 
267 (1,20). The duration of antibiotic treatment can be shortened based on both the serial serum PCT

268 levels and clinical assessment in specific clinical circumstances. However, this practice is not

269 endorsed for decision-making upon initiation of treatment (20).

270 Bacterial HAP/VAP can be differentiated from other non-infective etiologies, and deciding

271 whether antibiotic treatment can be stopped are possible in case of a serum PCT levels $<0.5 \mathrm{ng} / \mathrm{mL}$

$272(22)$.

273

$274 \quad 3.2 .5 \quad$ Microbiological diagnosis

275 It may not be always feasible to collect a bacteriological sample and modify the antibiotic therapy

276 accordingly. In addition, the yield of cultures from respiratory samples is not very high. In

277 practice, both qualitative and quantitative samples lose their sensitivity and specificity when 278 antibiotics have recently been started or modified (26). So, both clinical and bacteriological 279 assessments have to be combined to appropriately diagnose and manage HAP/VAP (22).

281 Definite Diagnosis:

282 The criteria for a definite diagnosis are:

283 - Positive blood culture in the absence of extrapulmonary infections,

284 - Positive pleural fluid culture, transthoracic biopsy, tracheobronchial aspirates (TBAS $\geq 10^{5}$

$285 \mathrm{CFU} / \mathrm{ml})$, protected specimen brushing (PSB) $\left(\geq 10^{3} \mathrm{CFU} / \mathrm{ml}\right)$, or bronchoalveolar lavage

$286 \quad(\mathrm{BAL})\left(\geq 10^{4} \mathrm{CFU} / \mathrm{ml}\right)$

287 - Seroconversion (4-fold increase of immunoglobulin G titer) for Chlamydia pneumoniae or 288 Legionella pneumophila $>1: 128$, Coxiella burnetii $>1: 80$, and respiratory viruses (influenza 289 virus A and B, parainfluenza virus 1-3, respiratory syncytial virus, adenovirus). 
293 Presumptive Diagnosis:

294 Predominant microorganism in a sputum sample compatible with Gram stain result.

$296 \quad 3.2 .6$ Lower respiratory tract sampling techniques

297 To identify the causative agent of NP in intubated patients, it is recommended to perform a 298 qualitative or quantitative or semi-quantitative (preferred) analysis of the respiratory secretions 299 taking into consideration the quality of the respiratory samples (20). The European guidelines 300 recommend to obtain the distal quantitative samples before antibiotic treatment, since negative 301 results may be observed if samples are obtained within 48 hours of starting antibiotic therapy (20). 302 Using distal quantitative cultures may reduce antibiotic overuse and consequently decrease the risk 303 of bacterial resistance and reduce health expenditure (20).

304 Samples of respiratory secretions can be obtained using non-invasive or invasive techniques 305 (Table 3; 20). Also, the diagnosis of HAP/VAP is established using various sampling techniques 306 like bronchoscopic or non-bronchoscopic BAL, endotracheal aspirate (ETA), and PSB (22). If a 307 diagnosis of VAP is suspected, individual preferences, local expertise, and cost will guide the 308 choice of the preferred method for lower respiratory tract sample collection (bronchoscopic or 309 non-bronchoscopic, blind or targeted); nevertheless, blind ETA sampling is the easiest and is 310 equally useful (22). Routine ETA culture is not recommended. Whenever feasible, an antibiogram 311 should be requested (Figure 1; 22). 
314 Table 3. Advantages and disadvantages of invasive and non-invasive sampling techniques

\begin{tabular}{|c|c|c|}
\hline & Advantages & Disadvantages \\
\hline $\begin{array}{l}\text { Non-invasive } \\
\text { qualitative cultures }\end{array}$ & $\begin{array}{l}\text { - Detect the presence or absence of } \\
\text { pathogens (31) } \\
\text { - Simple and non-invasive } \\
\text { techniques (32) }\end{array}$ & $\begin{array}{l}\text { - Samples are often contaminated } \\
\text { by the flora colonizing the upper } \\
\text { tracts and are therefore less } \\
\text { specific (32) } \\
\text { - May overestimate the presence of } \\
\text { bacteria in the initial examination } \\
\text { of the samples, which can lead to } \\
\text { excessive antibiotic use (20) }\end{array}$ \\
\hline $\begin{array}{l}\text { Invasive quantitative } \\
\text { cultures }\end{array}$ & $\begin{array}{l}\text { - Differentiate between infection } \\
\text { and colonization (31) } \\
\text { - Achieve reliable identification of } \\
\text { the causative pathogen (32) } \\
\text { - Can guide antimicrobial } \\
\text { treatment (20) }\end{array}$ & $\begin{array}{l}\text { - Need qualified personnel } \\
\text { - There is potential associated risks } \\
\text { on the patient, in addition to the } \\
\text { associated costs }(20,33)\end{array}$ \\
\hline
\end{tabular}




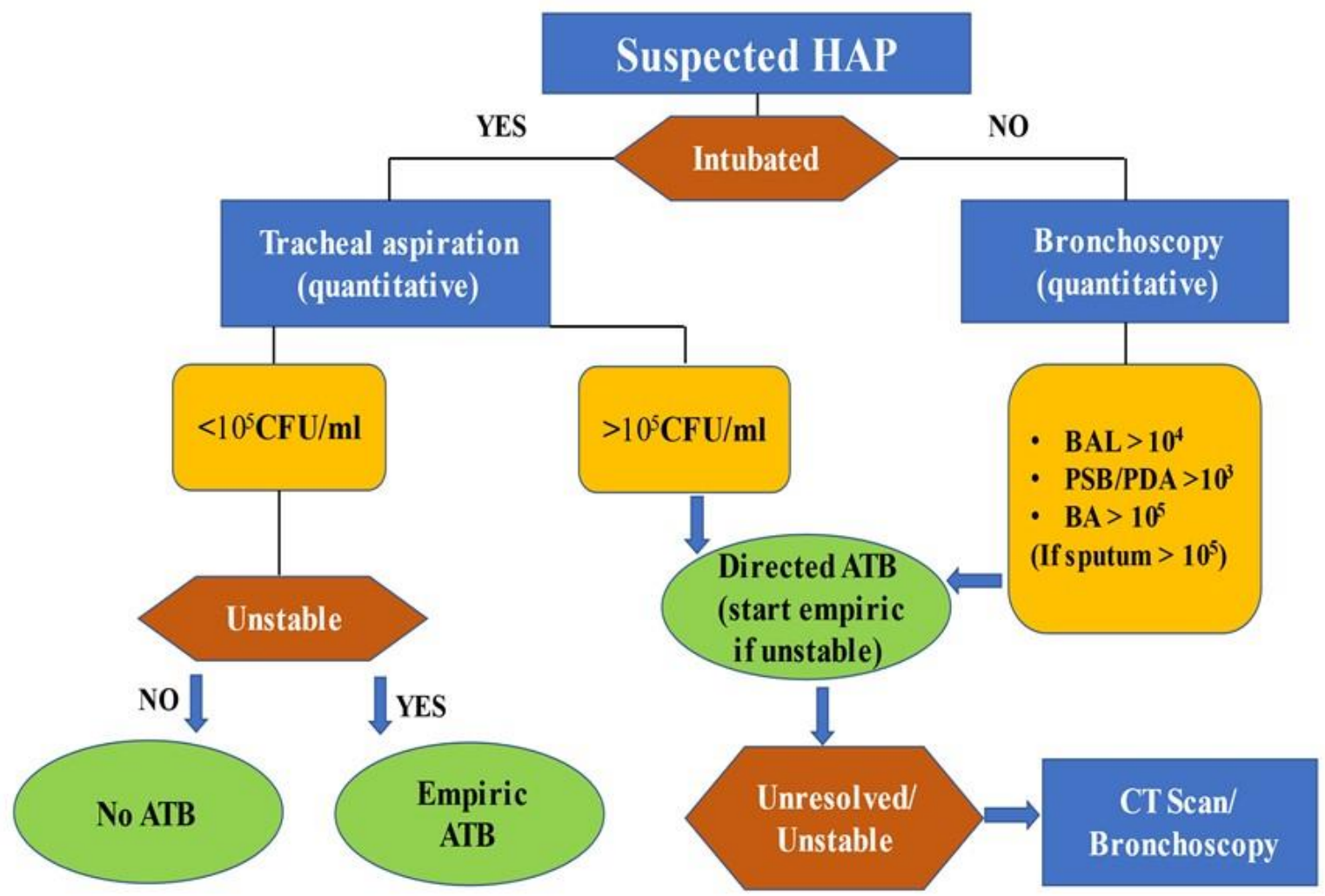

317 Figure 1. Algorithm for managing suspected HAP

318 ATB: antibiotic; BA: bronchial aspirate; BAL: bronchoalveolar lavage; CFU: colony-forming 319 unit; CT: computer tomography; HAP: hospital-acquired pneumonia; PDA: protective distal 320 aspirate; PSB: protected specimen brushing.

Recommendations

- We recommend assessing patients clinically through temperature charting, tracheobronchial

324 secretion culture and volume and purulence assessment, evaluation for chest radiograph 325 abnormality resolution, determination of white blood cell count and $\mathrm{PaO}_{2} / \mathrm{FiO}_{2}$, and calculation of a relevant score. 
- We suggest performing a routine bedside clinical assessment in patients receiving antibiotic treatment for VAP/HAP.

- We recommend performing a qualitative or quantitative (preferred) or semi-quantitative analysis of the respiratory secretions to identify the causative agent of NP in intubated patients.

- In a patient suspected of having VAP, the preferred method for lower respiratory tract sample collection (blind or targeted, bronchoscopic or non-bronchoscopic) depends upon individual preferences, local expertise, and associated cost.

- We recommend obtaining lower respiratory tract samples (distal quantitative, proximal quantitative, qualitative) to de-escalate and narrow the initial empiric antibiotic therapy.

- We do not recommend using PCT and CRP alone to diagnose HAP/VAP, or to initiate or reduce the duration of antimicrobial therapy.

- We suggest combining both clinical and bacteriological strategies to appropriately diagnose and manage HAP/VAP.

\subsection{MDROs Risk Factors}

MDR P. aeruginosa, extended spectrum beta-lactamase-producing Enterobacterales (ESBL-E), methicillin-resistant S. aureus (MRSA), Acinetobacter baumannii and carbapenem-resistant Enterobacterales (CRE) are the MDROs most commonly involved in NP (Table 4). Knowledge of the local epidemiology is essential since there are significant differences in the local prevalence of each MDRO (34). MDR Pseudomonas is defined as a pathogen which is resistant to at least one agent in three or more antibiotic classes (35). 
351 3.4. VAP Prevention (level of evidence)

352 Various organizations have proposed recommendations for VAP prevention. The ones established 353 by the Society for Healthcare Epidemiology of America (SHEA) and the Infectious Diseases 354 Society of America (IDSA) are evidence-based and include the following (based on level of 355 evidence) (36):

356 1. Basic practices to decrease average duration of MV, length of stay, morality and/or costs:

a. Use non-invasive positive pressure ventilation in selected populations (high)

b. Manage patients without sedation whenever possible (moderate)

c. Interrupt sedation daily (high)

d. Assess readiness to extubate daily (high)

e. Perform spontaneous breathing trials with sedatives turned off (high)

f. Facilitate early mobility (moderate)

g. Utilize endotracheal tubes with subglottic secretion drainage ports for patients expected to require greater than 48 or 72 hours of MV (moderate)

h. Change the ventilator circuit only if visibly soiled or malfunctioning (high)

i. Elevate the head of the bed to 30 to $45^{\circ}$ (low, but low cost and simple)

\section{Special approaches}

a. Improve outcomes but not enough evidence on possible risks:

i. Selective oral or digestive decontamination (high, but insufficient data on longterm impact on antimicrobial resistance) 
b. May lower VAP but insufficient data on impact on MV duration, length of stay or mortality:

i. Regular oral care with chlorhexidine (moderate)

ii. Prophylactic probiotics (moderate)

iii. Ultrathin polyurethane endotracheal tube cuffs (low)

iv. Automated control of endotracheal tube cuff pressure (low)

v. Saline instillation before tracheal suctioning (low)

vi. Mechanical tooth brushing (low)

In addition, the Institute for Healthcare Improvement (IHI) has proposed a bundle which hypothetically provides synergy between different components including $(37,38)$ : elevation of the head of the bed, daily sedation interruption and assessment of readiness to extubate, peptic ulcer disease prophylaxis, deep venous thrombosis prophylaxis, and daily oral care with chlorhexidine. Other organizations have proposed recommendations that are summarized in Table 5.

Since Acinetobacter is of concern in the Levant region (7), the ESCMID recommendations to reduce the transmission of MDR-A. baumannii include (39):

a. Hand hygiene

b. Contact precautions for all colonized patients

c. Alert code for previously colonized patients and pre-emptive contact precautions

d. Education on MDR-A. baumannii

e. Environmental cleaning

f. Antimicrobial stewardship

g. Active surveillance as an additional measure, but bathing with chlorhexidine was not supported. 
- We prefer to implement evidence-based preventive measures to lower the rate of VAP and improve patient outcomes.

\subsection{Treatment of HAP/VAP}

401 Inappropriate antibiotic treatment is an important modifiable prognostic factor that may increase 402 mortality in severe infections (40,41). Timeliness and appropriateness of antibiotic therapy is an 403 important consideration in NP.

\section{$405 \quad 3.5 .1 \quad$ HAP risk factors}

406 The risk factors of HAP are $(8,42-46)$ :

407 1. Patient-related factors: acute or chronic severe disease, coma, hypotension, malnutrition, 408 prolonged hospitalization, metabolic acidosis, smoking and comorbidities (such as disorders 409 of the central nervous system, chronic obstructive pulmonary disease (COPD), respiratory 410 insufficiency diabetes mellitus, alcoholism, and chronic renal failure).

411 2. Management-related factors: extended/inappropriate antibiotic treatment, administration of 412 sedatives, gastric acid suppressive therapy, corticosteroids and other immunosuppressants, and 413 prolonged surgical procedures (especially at the thoracic or abdominal levels).

414 3. Infection prevention-related factors: hand hygiene compliance failure or inappropriate care 415 of respiratory support equipment. 
418 The selection of appropriate antibiotic regimen and treatment duration are key elements to avoid 419 the emergence of bacterial resistance and achieve the best outcomes. While the duration of therapy 420 for MDROs is not clearly defined, the European guidelines recommend a duration of antibiotic 421 treatment for HAP of maximum 7 days. To avoid multidrug resistance, antibiotic treatment is 422 recommended for 7-8 days in patients with VAP without other respiratory comorbidities (such as 423 lung abscess, lung cavitation, pulmonary empyema, or necrotizing pneumonia), and who present 424 a good therapeutic response. Patients with inappropriate initial empiric therapy may need longer 425 courses of treatment which should be individualized to the patient's clinical response and 426 microbiological findings (20). In patients with $P$. aeruginosa pneumonia who have no significant 427 comorbidities, who defervesce and improve clinically within the first week of therapy, and who 428 have infection with a susceptible $P$. aeruginosa isolate can be treated with regimens of 7 to 10 429 days. However, based on expert opinion, longer treatment durations (e.g., from 10 to 21 days) may 430 be warranted for patients with serious underlying conditions (e.g., neutropenia), concurrent 431 bloodstream infection, a poor or slow response to therapy, and/or a partially susceptible or 432 multidrug-resistant strain (47). Short duration of treatment could lead to decreased antibiotic 433 exposure during hospitalization in the ICU and increased risk of MDROs. Empirical antimicrobial 434 therapy is selected based on risk factors, previous colonization, and local microbiology. Then, de435 escalation is done depending on the type of isolated pathogens and the possible advantages of one 436 antimicrobial over others.

437 Clinical scores, such as CPIS or CarbaSCORE (48), and non-specific biomarkers, such as PCT 438 and CRP, are tools that can guide therapy and clinical decision-making to appropriately begin or 439 stop antibiotic treatment (49). 
440 New treatment options are currently available in Lebanon with the approval of two beta-

441 lactam/beta-lactamase inhibitor antibiotics namely CFT/TAZ and CAZ/AVI for patients with

442 suspected MDRO infection. These agents demonstrated an appropriate activity and clinical

443 efficacy against ESBL-Enterobacterales and MDR $P$. aeruginosa in clinical trials $(50,51)$ with less

444 risk for emergence of resistance. They are considered good options in the armamentarium

445 particularly for carbapenem-sparing strategies in an antimicrobial stewardship policy $(52,53)$.

446 For infections with MDR Acinetobacter, inhaled colistin has been found to be of benefit. In one

447 study, a response rate of $80 \%$ was observed when using inhaled colistin as adjunctive therapy to

448 intravenous antibiotics for VAP caused by drug-resistant Gram-negative bacilli, predominantly $A$.

449 baumannii (54). Unless other options are available, it is preferred to use inhaled colistin for patients

450 with severe pneumonia due to A. baumannii that is resistant to beta-lactams and carbapenems (i.e.,

451 sensitive to colistin only) since lung concentration attained intravenously is low. Other studies

452 have showed that tigecycline was associated with a good response rate when used in patients with

453 VAP due to MDR A. baumannii $(55,56)$.

454 Ceftobiprole, a fifth-generation broad-spectrum cephalosporin, showed a limited activity against

455 A. baumannii (57-59).

456 Studies have shown that CFT/TAZ is a good choice to treat $P$. aeruginosa $(60,61)$ infections, and

457 ESBL-producing Enterobacterales infections (62). CFT/TAZ presents potent in-vitro activity

458 against $P$. aeruginosa including the MDR strains, with less resistance than the current anti-

459 pseudomonal agents (63). CFT/TAZ also exhibits the lowest mutant prevention concentration 460 (MPC) against $P$. aeruginosa, as well as colistin and quinolones (2 mg/L) (61). The ASPECT-NP

461 clinical trial demonstrated that CFT/TAZ was non-inferior to meropenem regarding 28-day all462 cause mortality, showed a trend toward reduced mortality in the subset of patients with HAP who 
463 required invasive $\mathrm{MV}$ (mortality at 28 days, $24.2 \%$ vs $37 \%$ ) and in patients who failed their initial 464 antibiotic treatment (mortality at 28 days, $22.6 \%$ vs 45\%), and achieved higher levels of 465 microbiological cure in pneumonia caused by P. aeruginosa (51).

466 A retrospective study evaluated real-world clinical experiences with CFT/TAZ to treat severe 467 ESBL-producing Enterobacterales infections. Around $84 \%$ of total cases and $78 \%$ of patients with 468 HAP showed a successful clinical outcome. Interestingly, no clinical failure was reported among 469 patients with CFT/TAZ administered as an empiric therapy compared to patients who had received 470 CFT/TAZ as a targeted or rescue therapy (64).

471 A study assessing the antimicrobial susceptibility of Gram-negative respiratory isolates from ICU 472 patients in hospitals in USA and Europe (SMART 2018) showed that co-resistance existed in 473 commonly prescribed first-line beta-lactam antibiotics; a pathogen that was non-susceptible to one 474 agent had a susceptibility rate of $<35 \%$ to other beta-lactams. For instance, when the Pseudomonas 475 isolates were non-susceptible to ceftazidime, susceptibility rate to piperacillin/tazobactam or 476 meropenem was very low, $7 \%$ and $27.2 \%$ respectively (65). These data can guide empiric therapy 477 in patients who fail initial antibiotic therapy.

478 CAZ/AVI is a good choice for patients with bacteremia who required rescue treatment in infections 479 caused by KPC-producing Enterobacterales (66), and infections caused by a CAZ/AVI-susceptible 480 OXA-48 strains (67), as well as infections caused by metallo- $\beta$-lactamase-producing 481 Enterobacterales when combined with aztreonam (68). It is associated with improved survival rates 482 in case of infections caused by KPC-producing Enterobacterales (66). The panel recommends the 483 following algorithm for the management of HAP/VAP based on risks for MDROs (Figure 2). 


\section{Recommendations}

486 - We recommend antibiotic treatment for no longer than 7 days in patients with HAP.

487 We recommend a duration of antibiotic treatment of 7-8 days in patients with VAP (except in 488 those caused by $P$. aeruginosa where, as discussed above, treatment can be prolonged in certain 489 cases).

490 - CFT/TAZ and CAZ/AVI are considered good options in patients with HAP/VAP caused by 491 ESBL-Enterobacterales and MDR P. aeruginosa.

492 - CFT/TAZ and CAZ/AVI are considered good options in the implementation of a carbapenem$493 \quad$ sparing strategy in an antibiotic stewardship program.

494 - We suggest using inhaled colistin for patients with severe pneumonia due to A. baumannii that 495 is resistant to beta-lactams and carbapenems. 
501 resistant; NP: nosocomial pneumonia; OXA-48: OXA-48 carbapenemase; PCR: polymerase chain reaction; PIP/TAZ,

502 piperacillin/tazobactam; R: resistance; spp.: species plural; TAT: targeted antimicrobial treatment; VAP: ventilator-associated 503 pneumonia; vHAP: ventilated hospital-acquired pneumonia. †Diabetes, COPD, moderate/severe renal/liver disease, 504 immunosuppression/neutropenia, elderly patients, solid tumor, structural lung disease, organ transplantation, hemodialysis *If Oxa-48 505 susceptible to CAZ/AVI. Adapted from Montravers P. et al, 2018 (17) and Zaragoza R et al., 2020 (17,53). 
508 An antimicrobial stewardship strategy for carbapenems did not impair clinical outcomes, and it 509 was associated with a lower rate of adverse drug reactions, lower incidence of carbapenem510 resistant $A$. baumannii infections, and a lower incidence of Clostridium difficile-associated 511 diarrhea (69). Considering the aforementioned results, implementing a carbapenem-sparing 512 strategy through an AMS program would be beneficial in terms of clinical outcomes and bacterial 513 resistance.

514 Experience from the Saint George Hospital University Medical Center (70) and the American 515 University of Beirut Medical Center (Infection Control and Prevention Program [ICPP], two major 516 hospitals in Lebanon, has shown that carbapenem-sparing strategies in managing ICU infections 517 were successful in improving carbapenem consumption and eliminating MDROs including $A$. 518 baumannii.

\section{3.7. COVID-19 and Influenza Virus Pandemics}

522 Secondary bacterial pneumonia is a complication of coronavirus disease 2019 (COVID-19) which 523 can be associated with worse outcomes (71). A meta-analysis showed that around 7\% of COVID52419 patients had a bacterial infection, out of which $14.3 \%$ were secondary infections (72). Bacterial 525 co-infection in patients with influenza virus infections was significantly associated with higher 526 morbidity and mortality (73).

527 The hallmark of the clinical presentation in patients with secondary bacterial pneumonia is the 528 exacerbation of fever and respiratory symptoms after initial improvement in the symptoms of acute 529 viral infection. Fever may abate for one or more days of viral infection, but instead of continuing 
530 to improve, the patient with secondary bacterial pneumonia relapses with higher fever, cough, 531 production of purulent sputum, and radiographic evidence of new pulmonary infiltrates. The most 532 common bacterial pathogens found in bacterial superinfections after influenza virus pneumonia 533 are Gram-positive bacteria such as Streptococcus pneumonia and S. aureus including MRSA (73). 534 Conversely, bacterial superinfections after COVID-19 infection are mostly caused by Gram535 negative bacteria such as A. baumannii, P. aeruginosa, and Klebsiella pneumonia, and fungi such 536 as Aspergillus (74). A recent study showed that patients with COVID-19 who required MV were 537 significantly more likely to develop VAP than patients who required MV for other reasons with 538 an incidence density of 28/1000 ventilator days versus $13 / 1000$ (p value $=0,009$ ) respectively and 539 the mortality rate for COVID-19 VAP was higher than for VAP in non COVID-19 infected patients $540 \quad(75)$.

541 In the context of reduced routine invasive microbiological investigation (bronchoscopy), the 542 extensive use of broad-spectrum empirical antibiotics should be avoided.

544 4. Conclusion

545 These guidelines represent a major step towards establishing Lebanese national guidelines for the 546 management of HAP/VAP. They also emphasize on implementing evidence-based preventive 547 measures to lower the rate of VAP and improve patient outcomes, and on timeliness and 548 appropriateness of antibiotic therapy for the management of HAP/VAP.

551 5. List of Abbreviations

552 ALAT: Asociación Latinoamericana del Tórax 
553 AMG: aminoglycoside

554 AMS: antimicrobial stewardship

555 APACHE II: Acute Physiology and Chronic Health Evaluation II

556 ARDS: acute respiratory distress syndrome

557 AT: antimicrobial therapy

558 ATB: antibiotic

559 AUBMC: American University of Beirut Medical Center

560 AVI: avibactam

561 AZT: aztreonam

562 BA: bronchial aspirate

563 BAL: bronchoalveolar lavage

564 CAP: community-acquired pneumonia

565 CAZ: ceftazidime

566 CFT: ceftolozane

567 CFU: colony-forming unit

568 CPE: carbapenemase-producing Enterobacterales

569 CPIS: Clinical Pulmonary Infection Scale

570 CRP: C-reactive protein

571 CT: computer tomography

572 EAT: empirical antimicrobial treatment

573 ECDC: European Center for Disease Prevention and Control

574 ERS: European Respiratory Society

575 ESBL-E: extended spectrum beta-lactamase-producing Enterobacterales 
576 ESCMID: European Society of Clinical Microbiology and Infectious Diseases

577 ESICM: European Society of Intensive Care Medicine

578 ETA: endotracheal aspirate

$579 \mathrm{FiO}_{2}$ inspiratory oxygen fraction

580 HAP: hospital-acquired pneumonia

581 ICPP: Infection Control and Prevention Program

582 ICS: Indian Chest Society

583 ICU: intensive care unit

584 IHI: Institute for Healthcare Improvement

585 KPC: Klebsiella pneumoniae carbapenemase

586 LPS: Lebanese Pulmonary Society

587 LSCCM: Lebanese Society of Critical Care Medicine

588 LSIDCM: Lebanese Society of Infectious Diseases and Clinical Microbiology

589 MDR: multidrug-resistant

590 MDROs: multidrug-resistant organisms

591 MRSA: methicillin-resistant Staphylococcus aureus

592 MV: mechanical ventilation

593 NCCP: National College of Chest Physicians

594 NHSN: National Healthcare Safety Network

595 NP: nosocomial pneumonia

596 ODIN: Organ Dysfunction and Infection System

597 OXA-48: OXA-48 carbapenemase

$598 \mathrm{PaO}_{2}$ : arterial oxygen pressure 
599 PCR: polymerase chain reaction

600 PCT: procalcitonin

601 PDA: protective distal aspirate

602 PIP: piperacillin

603 PSB: protected specimen brushing

604 R: resistance

605 RT-PCR: reverse transcription polymerase chain reaction

606 SAPS II: Simplified Acute Physiological Score II

607 SEPAR: Spanish Society of Pulmonology and Thoracic Surgery

608 SOFA: Sequential Organ Failure Assessment

609 Spp.: species plural

610 TAT: targeted antimicrobial treatment

611 TAZ: tazobactam

612 TBAS: tracheobronchial aspirates

613 USA: United States of America

614 VAP: ventilator-associated pneumonia

615 vHAP: ventilated-HAP

616

617

618 6. Declarations

619 Ethics approval and consent to participate

620 Not applicable.

621 


\section{Consent for publication}

623 Not applicable.

624

625 Availability of data and materials

626 Data sharing is not applicable to this article as no datasets were generated or analysed during the 627 current study.

628

629 Competing interests

630 Moussa Riachy, Claude Afif, Jacques Choucair, Patricia Yazbeck, Madonna J. Matar, Zeina Aoun631 Bacha, Wajdy Abi Saleh, Georges S. Juvelekian, Nadine Yared, Pierre Bou Khalil, Viviane 632 Chalhoub, Ralph Nehme, Youssef Haddad, Salah Zeineddine, and Souha S. Kanj declare that they 633 have no competing interests.

634 Aline El Zakhem has received personal fees for consultancies and lectures from MSD and Pfizer. 635 Rani Abu Khuzam has received personal fees for clinical studies from Novartis.

636

$637 \quad$ Funding

638 Editorial and medical writing assistance was provided by Mohammad Yassine, BPharm, MSc 639 (major contribution) and Racha Aaraj, Pharm D, MSc, MPH from Phoenix Clinical Research, 640 Lebanon. Medical writing support was funded by MSD Lebanon. 
643 Dr. Souha Kanj and Dr. Moussa Riachi provided expert insight and guidance on the development 644 of this manuscript. All authors provided expert input at each round of review of the paper. They 645 all contributed to the development of the manuscript and approved the final version.

646

647 Acknowledgements

648 Editorial and medical writing assistance was provided by Mohammad Yassine, BPharm, MSc 649 (major contribution) and Racha Aaraj, Pharm D, MSc, MPH from Phoenix Clinical Research, 650 Lebanon. Medical writing support was funded by MSD Lebanon. The views and opinions 651 expressed are those of the authors only.

652

653 Authors' information

654 Dr. Madonna J. Matar is the President of the Lebanese Society of Infectious Diseases and Clinical 655 Microbiology (LSIDCM). Dr. Claude Afif is the Vice President of the LSIDCM. Dr. Patricia 656 Yazbeck is the President of the Lebanese Society of Critical Care Medicine (LSCCM) and Dr. 657 Wajdy Abi Saleh is the Vice President of the LSCCM. Dr. Zeina Aoun-Bacha is the President of 658 the Lebanese Pulmonary Society (LPS) and Dr. Georges S. Juvelekian is the Vice President of the 659 LPS.

660

661

662

7. References

663 1. Kalil AC, Metersky ML, Klompas M, Muscedere J, Sweeney DA, Palmer LB, et al. Management 664 of Adults With Hospital-acquired and Ventilator-associated Pneumonia: 2016 Clinical Practice 
Guidelines by the Infectious Diseases Society of America and the American Thoracic Society. Clin Infect Dis. 2016;63(5):e61-111.

2. Dudeck MA, Weiner LM, Allen-Bridson K, Malpiedi PJ, Peterson KD, Pollock DA, et al. National Healthcare Safety Network (NHSN) Report, Data Summary for 2012, Device-associated Module. Am J Infect Control. 2013;41(12):1148-66.

3. Giuliano KK, Baker D, Quinn B. The epidemiology of nonventilator hospital-acquired pneumonia in the United States. American Journal of Infection Control. 2018;46(3):322-7.

4. Healthcare-associated infections in intensive care units - Annual Epidemiological Report for 2016 [Internet]. European Centre for Disease Prevention and Control. 2018 [cited 2020 Dec 12]. Available from: https://www.ecdc.europa.eu/en/publications-data/healthcare-associated-infections-intensivecare-units-annual-epidemiological-0

5. Walter J, Haller S, Quinten C, Kärki T, Zacher B, Eckmanns T, et al. Healthcare-associated pneumonia in acute care hospitals in European Union/European Economic Area countries: an analysis of data from a point prevalence survey, 2011 to 2012. Euro Surveill. 2018;23(32).

6. El-Saed A, Al-Jardani A, Althaqafi A, Alansari H, Alsalman J, Al Maskari Z, et al. Ventilatorassociated pneumonia rates in critical care units in 3 Arabian Gulf countries: A 6-year surveillance study. Am J Infect Control. 2016;44(7):794-8.

7. Kanafani ZA, El Zakhem A, Zahreddine N, Ahmadieh R, Kanj SS. Ten-year surveillance study of ventilator-associated pneumonia at a tertiary care center in Lebanon. J Infect Public Health. 2019;12(4):492-5.

8. Micek ST, Chew B, Hampton N, Kollef MH. A Case-Control Study Assessing the Impact of Nonventilated Hospital-Acquired Pneumonia on Patient Outcomes. Chest. 2016;150(5):1008-14.

9. Kohlenberg A, Schwab F, Behnke M, Geffers C, Gastmeier P. Pneumonia associated with invasive and noninvasive ventilation: an analysis of the German nosocomial infection surveillance system database. Intensive Care Med. 2010;36(6):971-8.

10. Talbot GH, Das A, Cush S, Dane A, Wible M, Echols R, et al. Evidence-Based Study Design for Hospital-Acquired Bacterial Pneumonia and Ventilator-Associated Bacterial Pneumonia. The Journal of Infectious Diseases. 2019;219(10):1536-44. 
11. Muscedere JG, Day A, Heyland DK. Mortality, attributable mortality, and clinical events as end points for clinical trials of ventilator-associated pneumonia and hospital-acquired pneumonia. Clin Infect Dis. 2010;51 Suppl 1:S120-125.

12. Kollef MH, Hamilton CW, Ernst FR. Economic impact of ventilator-associated pneumonia in a large matched cohort. Infect Control Hosp Epidemiol. 2012;33(3):250-6.

13. Weiner LM, Webb AK, Limbago B, Dudeck MA, Patel J, Kallen AJ, et al. Antimicrobial-Resistant Pathogens Associated With Healthcare-Associated Infections: Summary of Data Reported to the National Healthcare Safety Network at the Centers for Disease Control and Prevention, 2011-2014. Infect Control Hosp Epidemiol. 2016;37(11):1288-301.

14. Jones RN. Microbial etiologies of hospital-acquired bacterial pneumonia and ventilator-associated bacterial pneumonia. Clin Infect Dis. 2010;51 Suppl 1:S81-87.

15. Awad LS, Abdallah DI, Mugharbil AM, Jisr TH, Droubi NS, El-Rajab NA, et al. An antibiotic stewardship exercise in the ICU: building a treatment algorithm for the management of ventilatorassociated pneumonia based on local epidemiology and the 2016 Infectious Diseases Society of America/American Thoracic Society guidelines. Infect Drug Resist. 2018;11:17-28.

16. Kanafani ZA, Kara L, Hayek S, Kanj SS. Ventilator-associated pneumonia at a tertiary-care center in a developing country: incidence, microbiology, and susceptibility patterns of isolated microorganisms. Infect Control Hosp Epidemiol. 2003;24(11):864-9.

17. Zaragoza R, Vidal-Cortés P, Aguilar G, Borges M, Diaz E, Ferrer R, et al. Update of the treatment of nosocomial pneumonia in the ICU. Crit Care. 2020;24(1):383.

18. Vallecoccia MS, Dominedò C, Cutuli SL, Martin-Loeches I, Torres A, De Pascale G. Is ventilated hospital-acquired pneumonia a worse entity than ventilator-associated pneumonia? Eur Respir Rev. 2020;29(157).

19. Salluh JIF, Souza-Dantas VC, Póvoa P. The current status of biomarkers for the diagnosis of nosocomial pneumonias. Curr Opin Crit Care. 2017;23(5):391-7.

20. Torres A, Niederman MS, Chastre J, Ewig S, Fernandez-Vandellos P, Hanberger H, et al. International ERS/ESICM/ESCMID/ALAT guidelines for the management of hospital-acquired pneumonia and ventilator-associated pneumonia: Guidelines for the management of hospital- 
acquired pneumonia (HAP)/ventilator-associated pneumonia (VAP) of the European Respiratory Society (ERS), European Society of Intensive Care Medicine (ESICM), European Society of Clinical Microbiology and Infectious Diseases (ESCMID) and Asociación Latinoamericana del Tórax (ALAT). Eur Respir J. 2017;50(3).

21. Rotstein C, Evans G, Born A, Grossman R, Light RB, Magder S, et al. Clinical practice guidelines for hospital-acquired pneumonia and ventilator-associated pneumonia in adults. Can J Infect Dis Med Microbiol. 2008;19(1):19-53.

22. Gupta D, Agarwal R, Aggarwal AN, Singh N, Mishra N, Khilnani GC, et al. Guidelines for diagnosis and management of community- and hospital-acquired pneumonia in adults: Joint ICS/NCCP(I) recommendations. Lung India. 2012;29(Suppl 2):S27-62.

23. Luna CM, Blanzaco D, Niederman MS, Matarucco W, Baredes NC, Desmery P, et al. Resolution of ventilator-associated pneumonia: prospective evaluation of the clinical pulmonary infection score as an early clinical predictor of outcome. Crit Care Med. 2003;31(3):676-82.

24. Seligman R, Meisner M, Lisboa TC, Hertz FT, Filippin TB, Fachel JMG, et al. Decreases in procalcitonin and $\mathrm{C}$-reactive protein are strong predictors of survival in ventilator-associated pneumonia. Crit Care. 2006;10(5):R125.

25. Fartoukh M, Maitre B, Honoré S, Cerf C, Zahar J-R, Brun-Buisson C. Diagnosing pneumonia during mechanical ventilation: the clinical pulmonary infection score revisited. Am J Respir Crit Care Med. 2003;168(2):173-9.

26. Torres A, Niederman MS, Chastre J, Ewig S, Fernandez-Vandellos P, Hanberger H, et al. Summary of the international clinical guidelines for the management of hospital-acquired and ventilatoracquired pneumonia. ERJ Open Res. 2018;4(2).

27. Seligman R, Seligman BGS, Teixeira PJZ. Comparing the accuracy of predictors of mortality in ventilator-associated pneumonia. J Bras Pneumol. 2011;37(4):495-503.

28. Liu D, Su L, Guan W, Xiao K, Xie L. Prognostic value of procalcitonin in pneumonia: A systematic review and meta-analysis. Respirology. 2016;21(2):280-8. 
29. Amour J, Birenbaum A, Langeron O, Le Manach Y, Bertrand M, Coriat P, et al. Influence of renal dysfunction on the accuracy of procalcitonin for the diagnosis of postoperative infection after vascular surgery. Crit Care Med. 2008;36(4):1147-54.

30. Nora D, Salluh J, Martin-Loeches I, Póvoa P. Biomarker-guided antibiotic therapy-strengths and limitations. Ann Transl Med. 2017;5(10):208.

31. Berton DC, Kalil AC, Teixeira PJZ. Quantitative versus qualitative cultures of respiratory secretions for clinical outcomes in patients with ventilator-associated pneumonia. Cochrane Database Syst Rev. 2014;(10):CD006482.

32. Díaz E, Martín-Loeches I, Vallés J. [Nosocomial pneumonia]. Enferm Infecc Microbiol Clin. 2013;31(10):692-8.

33. Blanquer J, Aspa J, Anzueto A, Ferrer M, Gallego M, Rajas O, et al. SEPAR Guidelines for Nosocomial Pneumonia. Arch Bronconeumol. 2011;47(10):510-20.

34. Beardsley JR, Williamson JC, Johnson JW, Ohl CA, Karchmer TB, Bowton DL. Using local microbiologic data to develop institution-specific guidelines for the treatment of hospital-acquired pneumonia. Chest. 2006;130(3):787-93.

35. Abrahamian FM, Deblieux PM, Emerman CL, Kollef MH, Kupersmith E, Leeper KV, et al. Health care-associated pneumonia: identification and initial management in the ED. Am J Emerg Med. 2008;26(6 Suppl):1-11.

36. Klompas M, Branson R, Eichenwald EC, Greene LR, Howell MD, Lee G, et al. Strategies to prevent ventilator-associated pneumonia in acute care hospitals: 2014 update. Infect Control Hosp Epidemiol. 2014;35(8):915-36.

37. Al-Thaqafy MS, El-Saed A, Arabi YM, Balkhy HH. Association of compliance of ventilator bundle with incidence of ventilator-associated pneumonia and ventilator utilization among critical patients over 4 years. Ann Thorac Med. 2014;9(4):221-6.

38. Evans B. Best-practice protocols: VAP prevention. Nurs Manage. 2005;36(12):10, 12, 14 passim.

39. Tacconelli E, Cataldo MA, Dancer SJ, De Angelis G, Falcone M, Frank U, et al. ESCMID guidelines for the management of the infection control measures to reduce transmission of multidrug-resistant Gram-negative bacteria in hospitalized patients. Clin Microbiol Infect. 2014;20 Suppl 1:1-55. 
775

776

777

778

779

780

781

782

783

784

785

786

787

788

789

790

791

792

793

794

795

796

797

798

799

800

801

802

40. Zilberberg MD, Shorr AF, Micek ST, Vazquez-Guillamet C, Kollef MH. Multi-drug resistance, inappropriate initial antibiotic therapy and mortality in Gram-negative severe sepsis and septic shock: a retrospective cohort study. Crit Care. 2014;18(6):596.

41. Kollef MH. Treatment of ventilator-associated pneumonia: get it right from the start. Crit Care Med. 2003;31(3):969-70.

42. American Thoracic Society, Infectious Diseases Society of America. Guidelines for the management of adults with hospital-acquired, ventilator-associated, and healthcare-associated pneumonia. Am J Respir Crit Care Med. 2005;171(4):388-416.

43. Hospital-acquired pneumonia in adults: diagnosis, assessment of severity, initial antimicrobial therapy, and preventive strategies. A consensus statement, American Thoracic Society, November 1995. Am J Respir Crit Care Med. 1996;153(5):1711-25.

44. Sopena N, Heras E, Casas I, Bechini J, Guasch I, Pedro-Botet ML, et al. Risk factors for hospitalacquired pneumonia outside the intensive care unit: a case-control study. Am J Infect Control. 2014;42(1):38-42.

45. Di Pasquale M, Aliberti S, Mantero M, Bianchini S, Blasi F. Non-Intensive Care Unit Acquired Pneumonia: A New Clinical Entity? Int J Mol Sci. 2016;17(3):287.

46. Herzig SJ, Howell MD, Ngo LH, Marcantonio ER. Acid-suppressive medication use and the risk for hospital-acquired pneumonia. JAMA. 2009;301(20):2120-8.

47. Kanj SS, Sexton DJ. Pseudomonas aeruginosa pneumonia - UpToDate [Internet]. [cited 2021 Mar 9]. Available from: https://www.uptodate.com/contents/pseudomonas-aeruginosa-pneumonia

48. Teysseyre L, Ferdynus C, Miltgen G, Lair T, Aujoulat T, Lugagne N, et al. Derivation and validation of a simple score to predict the presence of bacteria requiring carbapenem treatment in ICU-acquired bloodstream infection and pneumonia: CarbaSCORE. Antimicrob Resist Infect Control. 2019;8:78.

49. Millot G, Voisin B, Loiez C, Wallet F, Nseir S. The next generation of rapid point-of-care testing identification tools for ventilator-associated pneumonia. Ann Transl Med. 2017;5(22):451.

50. Torres A, Zhong N, Pachl J, Timsit J-F, Kollef M, Chen Z, et al. Ceftazidime-avibactam versus meropenem in nosocomial pneumonia, including ventilator-associated pneumonia (REPROVE): a randomised, double-blind, phase 3 non-inferiority trial. Lancet Infect Dis. 2018;18(3):285-95. 
51. Kollef MH, Nováček M, Kivistik Ü, Réa-Neto Á, Shime N, Martin-Loeches I, et al. Ceftolozanetazobactam versus meropenem for treatment of nosocomial pneumonia (ASPECT-NP): a randomised, controlled, double-blind, phase 3, non-inferiority trial. Lancet Infect Dis. 2019;19(12):1299-311.

52. Bassetti M, Righi E, Vena A, Graziano E, Russo A, Peghin M. Risk stratification and treatment of ICU-acquired pneumonia caused by multidrug- resistant/extensively drug-resistant/pandrugresistant bacteria. Curr Opin Crit Care. 2018;24(5):385-93.

53. Montravers $\mathrm{P}$, Bassetti $\mathrm{M}$. The ideal patient profile for new beta-lactam/beta-lactamase inhibitors. Curr Opin Infect Dis. 2018;31(6):587-93.

54. Qureshi ZA, Hittle LE, O'Hara JA, Rivera JI, Syed A, Shields RK, et al. Colistin-resistant Acinetobacter baumannii: beyond carbapenem resistance. Clin Infect Dis. 2015;60(9):1295-303.

55. Curcio D, Fernández F, Vergara J, Vazquez W, Luna CM. Late onset ventilator-associated pneumonia due to multidrug-resistant Acinetobacter spp.: experience with tigecycline. J Chemother. 2009;21(1):58-62.

56. Metan G, Alp E, Yildiz O, Percin D, Aygen B, Sumerkan B. Clinical experience with tigecycline in the treatment of carbapenem-resistant Acinetobacter infections. J Chemother. 2010;22(2):110-4.

57. Awad SS, Rodriguez AH, Chuang Y-C, Marjanek Z, Pareigis AJ, Reis G, et al. A phase 3 randomized double-blind comparison of ceftobiprole medocaril versus ceftazidime plus linezolid for the treatment of hospital-acquired pneumonia. Clin Infect Dis. 2014;59(1):51-61.

58. Scheeren TWL. Ceftobiprole medocaril in the treatment of hospital-acquired pneumonia. Future Microbiol. 2015;10(12):1913-28.

59. Syed YY. Ceftobiprole medocaril: a review of its use in patients with hospital- or communityacquired pneumonia. Drugs. 2014;74(13):1523-42.

60. Mensa J, Barberán J, Soriano A, Llinares P, Marco F, Cantón R, et al. Antibiotic selection in the treatment of acute invasive infections by Pseudomonas aeruginosa: Guidelines by the Spanish Society of Chemotherapy. Rev Esp Quimioter. 2018;31(1):78-100.

61. Bassetti M, Vena A, Russo A, Croxatto A, Calandra T, Guery B. Rational approach in the management of Pseudomonas aeruginosa infections. Curr Opin Infect Dis. 2018;31(6):578-86. 
831 62. Bassetti M, Righi E, Carnelutti A, Graziano E, Russo A. Multidrug-resistant Klebsiella pneumoniae: challenges for treatment, prevention and infection control. Expert Rev Anti Infect Ther. 2018;16(10):749-61.

834

63. Goodlet KJ, Nicolau DP, Nailor MD. In Vitro Comparison of Ceftolozane-Tazobactam to Traditional Beta-Lactams and Ceftolozane-Tazobactam as an Alternative to Combination Antimicrobial Therapy for Pseudomonas aeruginosa. Antimicrob Agents Chemother. 2017;61(12).

64. Bassetti M, Vena A, Giacobbe DR, Falcone M, Tiseo G, Giannella M, et al. Ceftolozane/Tazobactam for Treatment of Severe ESBL-Producing Enterobacterales Infections: A Multicenter Nationwide Clinical Experience (CEFTABUSE II Study). Open Forum Infect Dis. 2020;7(5):ofaa139.

65. 40th International Symposium on Intensive Care \& Emergency Medicine. Critical Care. 2020;24(1):87.

66. Tumbarello M, Trecarichi EM, Corona A, De Rosa FG, Bassetti M, Mussini C, et al. Efficacy of Ceftazidime-Avibactam Salvage Therapy in Patients With Infections Caused by Klebsiella pneumoniae Carbapenemase-producing K. pneumoniae. Clin Infect Dis. 2019;68(3):355-64.

67. Alraddadi BM, Saeedi M, Qutub M, Alshukairi A, Hassanien A, Wali G. Efficacy of ceftazidimeavibactam in the treatment of infections due to Carbapenem-resistant Enterobacteriaceae. BMC Infectious Diseases. 2019;19(1):772.

68. Marshall S, Hujer AM, Rojas LJ, Papp-Wallace KM, Humphries RM, Spellberg B, et al. Can Ceftazidime-Avibactam and Aztreonam Overcome $\beta$-Lactam Resistance Conferred by Metallo- $\beta$ Lactamases in Enterobacteriaceae? Antimicrob Agents Chemother. 2017;61(4).

69. Lew KY, Ng TM, Tan M, Tan SH, Lew EL, Ling LM, et al. Safety and clinical outcomes of carbapenem de-escalation as part of an antimicrobial stewardship programme in an ESBL-endemic setting. J Antimicrob Chemother. 2015;70(4):1219-25.

70. Chamieh A, Nawfal TD, Ballouz T, Afif C, Juvelekian G, Hlais S, et al. Control and Elimination of Extensively Drug-Resistant Acinetobacter baumanii in an Intensive Care Unit. Emerg Infect Dis. 2019;25(10):1928-31.

71. Vaillancourt M, Jorth P. The Unrecognized Threat of Secondary Bacterial Infections with COVID19. mBio. 2020;11(4):e01806-20. 
872

873

72. Langford BJ, So M, Raybardhan S, Leung V, Westwood D, MacFadden DR, et al. Bacterial coinfection and secondary infection in patients with COVID-19: a living rapid review and metaanalysis. Clin Microbiol Infect. 2020;26(12):1622-9.

73. Rice TW, Rubinson L, Uyeki TM, Vaughn FL, John BB, Miller RR, et al. Critical Illness from 2009 Pandemic Influenza A (H1N1) Virus and Bacterial Co-Infection in the United States. Crit Care Med. 2012;40(5):1487-98.

74. Clancy CJ, Nguyen MH. COVID-19, superinfections and antimicrobial development: What can we expect? Clin Infect Dis. 2020;

75. Maes M, Higginson E, Pereira-Dias J, Curran MD, Parmar S, Khokhar F, et al. Ventilator-associated pneumonia in critically ill patients with COVID-19. Critical Care. 2021;25(1):25.

76. Torre-Cisneros J, Natera C, Mesa F, Trikic M, Rodríguez-Baño J. Clinical predictors of methicillinresistant Staphylococcus aureus in nosocomial and healthcare-associated pneumonia: a multicenter, matched case-control study. Eur J Clin Microbiol Infect Dis. 2018;37(1):51-6.

77. Torre-Cisneros J, Tejero García R, Natera Kindelán C, Font Ugalde P, Franco Álvarez de Luna F, Castón Osorio JJ, et al. [Risk factors of nosocomial pneumonia caused by methicillin-resistant Staphylococcus aureus]. Med Clin (Barc). 2012;138(3):99-106.

78. Metersky ML, Frei CR, Mortensen EM. Predictors of Pseudomonas and methicillin-resistant Staphylococcus aureus in hospitalized patients with healthcare-associated pneumonia. Respirology. 2016;21(1):157-63.

79. Buhl M, Peter S, Willmann M. Prevalence and risk factors associated with colonization and infection of extensively drug-resistant Pseudomonas aeruginosa: a systematic review. Expert Rev Anti Infect Ther. 2015;13(9):1159-70.

80. Fernández-Barat L, Ferrer M, De Rosa F, Gabarrús A, Esperatti M, Terraneo S, et al. Intensive care unit-acquired pneumonia due to Pseudomonas aeruginosa with and without multidrug resistance. $\mathbf{J}$ Infect. 2017;74(2):142-52.

81. Venier AG, Gruson D, Lavigne T, Jarno P, L'hériteau F, Coignard B, et al. Identifying new risk factors for Pseudomonas aeruginosa pneumonia in intensive care units: experience of the French national surveillance, REA-RAISIN. J Hosp Infect. 2011;79(1):44-8. 
82. Aloush V, Navon-Venezia S, Seigman-Igra Y, Cabili S, Carmeli Y. Multidrug-resistant Pseudomonas aeruginosa: risk factors and clinical impact. Antimicrob Agents Chemother. 2006;50(1):43-8.

83. Nakamura A, Miyake K, Misawa S, Kuno Y, Horii T, Kondo S, et al. Meropenem as predictive risk factor for isolation of multidrug-resistant Pseudomonas aeruginosa. J Hosp Infect. 2013;83(2):1535 .

84. Tartof SY, Kuntz JL, Chen LH, Wei R, Puzniak L, Tian Y, et al. Development and Assessment of Risk Scores for Carbapenem and Extensive $\beta$-Lactam Resistance Among Adult Hospitalized Patients With Pseudomonas aeruginosa Infection. JAMA Netw Open. 2018;1(6):e183927.

85. Gao B, Li X, Yang F, Chen W, Zhao Y, Bai G, et al. Molecular Epidemiology and Risk Factors of Ventilator-Associated Pneumonia Infection Caused by Carbapenem-Resistant Enterobacteriaceae. Front Pharmacol. 2019;10:262.

86. Sbrana F, Malacarne P, Bassetti M, Tascini C, Vegnuti L, Della Siega P, et al. Risk factors for ventilator associated pneumonia due to carbapenemase-producing Klebsiella pneumoniae in mechanically ventilated patients with tracheal and rectal colonization. Minerva Anestesiol. 2016;82(6):635-40.

87. Peralta G, Sánchez MB, Garrido JC, De Benito I, Cano ME, Martínez-Martínez L, et al. Impact of antibiotic resistance and of adequate empirical antibiotic treatment in the prognosis of patients with Escherichia coli bacteraemia. J Antimicrob Chemother. 2007;60(4):855-63.

88. Aydemir H, Tuz HI, Piskin N, Celebi G, Kulah C, Kokturk F. Risk factors and clinical responses of pneumonia patients with colistin-resistant Acinetobacter baumannii-calcoaceticus. World J Clin Cases. 2019;7(10):1111-21.

89. Zheng Y, Wan Y, Zhou L, Ye M, Liu S, Xu C, et al. Risk factors and mortality of patients with nosocomial carbapenem-resistant Acinetobacter baumannii pneumonia. Am J Infect Control. 2013;41(7):e59-63.

90. Cordes LG, Brink EW, Checko PJ, Lentnek A, Lyons RW, Hayes PS, et al. A cluster of Acinetobacter Pneumonia in foundry workers. Ann Intern Med. 1981;95(6):688-93. 
914 91. Centers for Disease Control and Prevention (CDC). Acinetobacter baumannii infections among 915 patients at military medical facilities treating injured U.S. service members, 2002-2004. MMWR Morb Mortal Wkly Rep. 2004;53(45):1063-6.

917 92. Scott P, Deye G, Srinivasan A, Murray C, Moran K, Hulten E, et al. An outbreak of multidrug918 resistant Acinetobacter baumannii-calcoaceticus complex infection in the US military health care system associated with military operations in Iraq. Clin Infect Dis. 2007;44(12):1577-84.

920

93. Álvarez-Lerma F, Palomar-Martínez M, Sánchez-García M, Martínez-Alonso M, ÁlvarezRodríguez J, Lorente L, et al. Prevention of Ventilator-Associated Pneumonia: The Multimodal Approach of the Spanish ICU "Pneumonia Zero" Program. Crit Care Med. 2018;46(2):181-8.

923

94. Bouadma L, Deslandes E, Lolom I, Le Corre B, Mourvillier B, Regnier B, et al. Long-term impact 924 of a multifaceted prevention program on ventilator-associated pneumonia in a medical intensive care unit. Clin Infect Dis. 2010;51(10):1115-22.

926

95. Berenholtz SM, Pham JC, Thompson DA, Needham DM, Lubomski LH, Hyzy RC, et al. Collaborative cohort study of an intervention to reduce ventilator-associated pneumonia in the intensive care unit. Infect Control Hosp Epidemiol. 2011;32(4):305-14.

929 8. Tables

930 Table 4. Risk factors of MDRO causing NP

\begin{tabular}{|c|ll|}
\hline MDRO & \multicolumn{1}{c|}{ Risk factors } \\
\hline & 0 & Age \\
& 0 & NP appearance $>6$ days after admission \\
MRSA (76-78) & 0 & NP development excluding summers \\
& $\circ$ & Respiratory diseases \\
& 0 & Respiratory infection/colonization caused by MRSA in the previous year \\
& 0 & Hospitalization in the previous 90 days \\
& 0 & Recent nursing home or hospital stay \\
\hline
\end{tabular}




\begin{tabular}{|c|c|}
\hline MDRO & Risk factors \\
\hline & $\begin{array}{l}\text { Recent exposure to fluoroquinolones or antibiotics treating Gram- } \\
\text { positive organisms }\end{array}$ \\
\hline $\begin{array}{c}\text { Pseudomonas } \\
\text { aeruginosa (79- } \\
\text { 84) }\end{array}$ & $\begin{array}{l}\circ \text { Increased age } \\
\circ \text { Length of MV } \\
\circ \text { Antibiotics at admission } \\
\circ \text { Transfer from a medical unit or ICU } \\
\circ \text { Admission in a ward with higher incidence of patients with } P . \\
\text { aeruginosa infections } \\
\circ \text { ICU stay } \\
\circ \text { Bedridden status } \\
\circ \text { Presence of invasive devices } \\
\circ \text { Prior use of certain antibiotics (broad-spectrum cephalosporins, } \\
\text { aminoglycosides, carbapenems, fluoroquinolones) } \\
\circ \text { Diabetes mellitus } \\
\circ \text { Surgery }\end{array}$ \\
\hline $\begin{array}{c}\text { Enterobacterales } \\
\text { (producing }\end{array}$ & $\begin{array}{l}\circ \text { Admission to ICU and antimicrobial use } \\
\circ \text { Invasive operation } \\
\circ \text { Duration of previous antibiotic therapy } \\
\circ \text { Male gender } \\
\circ \text { Admission from another healthcare facility } \\
\circ \text { Ventilation at any point before culture during the index hospitalization } \\
\circ \text { Receipt of any carbapenem in the prior } 30 \text { days }\end{array}$ \\
\hline
\end{tabular}




\begin{tabular}{|c|ll|}
\hline MDRO & \multicolumn{1}{|c|}{ Risk factors } \\
\hline & $\circ$ & Prior colonization with MRSA \\
& $\circ$ & Prior beta-lactam use, particularly carbapenems \\
& $\circ$ & Prior fluoroquinolone use \\
Acinetobacter & $\circ$ & Bedridden status \\
baumannii & $\circ$ & Debilitated status of patients in ICU \\
(52,88-92) & $\circ$ & Current or prior intensive care unit admission \\
& $\circ$ & Presence of a central venous catheter \\
& $\circ$ & MV \\
& $\circ$ & Hemodialysis \\
& $\circ$ & Malignancy \\
\hline
\end{tabular}

931 CRE: carbapenem-resistant Enterobacterales; ESBL: extended spectrum beta-lactamase; ICU:

932 intensive care unit; MDRO: multidrug-resistant organism; MRSA: methicillin-resistant

933 Staphylococcus aureus; MV: mechanical ventilation; NP: nosocomial pneumonia.

934

935 Table 5. Different VAP prevention bundles

\begin{tabular}{|c|c|c|c|c|c|c|c|}
\hline & Intervention & $\begin{array}{l}\text { SHE } \\
\text { A/ID } \\
\text { SA } \\
(36)\end{array}$ & $\begin{array}{c}\text { IHI } \\
\text { bundle } \\
(37,38)\end{array}$ & $\begin{array}{c}\text { Spanis } \\
\text { h } \\
\text { bundle } \\
\text { (93) }\end{array}$ & $\begin{array}{c}\text { Frenc } \\
\text { h } \\
\text { bundle } \\
(94)\end{array}$ & $\begin{array}{c}\text { Johns } \\
\text { Hopkin } \\
\text { s } \\
\text { bundle } \\
(95)\end{array}$ & $\begin{array}{l}\text { Level of } \\
\text { recommendati } \\
\text { on } \\
\text { (SHEA/IDSA) }\end{array}$ \\
\hline 1 & Head of bed elevation & B & $\mathrm{X}$ & $\mathrm{X}$ & $\mathrm{X}$ & $\mathrm{X}$ & Low \\
\hline
\end{tabular}




\begin{tabular}{|c|c|c|c|c|c|c|c|}
\hline & Intervention & $\begin{array}{r}\text { SHE } \\
\text { A/ID } \\
\text { SA } \\
(36)\end{array}$ & $\begin{array}{c}\text { IHI } \\
\text { bundle } \\
(37,38)\end{array}$ & $\begin{array}{c}\text { Spanis } \\
\text { h } \\
\text { bundle } \\
(93)\end{array}$ & $\begin{array}{c}\text { Frenc } \\
\text { h } \\
\text { bundle } \\
(94)\end{array}$ & $\begin{array}{c}\text { Johns } \\
\text { Hopkin } \\
\text { s } \\
\text { bundle } \\
(95)\end{array}$ & $\begin{array}{c}\text { Level of } \\
\text { recommendati } \\
\text { on } \\
\text { (SHEA/IDSA) }\end{array}$ \\
\hline 2 & $\begin{array}{l}\text { Non-invasive positive } \\
\text { pressure ventilation in } \\
\text { selected populations }\end{array}$ & B & & & & & High \\
\hline 3 & $\begin{array}{l}\text { Minimize sedation or } \\
\text { manage without } \\
\text { sedation whenever } \\
\text { possible }\end{array}$ & B & & $X$ & & $X$ & Moderate \\
\hline 4 & $\begin{array}{l}\text { Daily sedation } \\
\text { interruption }\end{array}$ & B & $\mathrm{X}$ & & & & High \\
\hline 5 & $\begin{array}{l}\text { Daily assessment of } \\
\text { readiness to extubate }\end{array}$ & B & $X$ & & & $X$ & High \\
\hline 6 & $\begin{array}{l}\text { Perform spontaneous } \\
\text { breathing trials with } \\
\text { sedatives turned off }\end{array}$ & B & & & & & High \\
\hline 7 & $\begin{array}{l}\text { Facilitate early } \\
\text { mobility }\end{array}$ & B & & & & & Moderate \\
\hline 8 & $\begin{array}{l}\text { Utilize endotracheal } \\
\text { tubes with subglottic }\end{array}$ & B & & & & & Moderate \\
\hline
\end{tabular}




\begin{tabular}{|c|c|c|c|c|c|c|c|}
\hline & Intervention & $\begin{array}{r}\text { SHE } \\
\text { A/ID } \\
\text { SA } \\
(36)\end{array}$ & $\begin{array}{c}\text { IHI } \\
\text { bundle } \\
(37,38)\end{array}$ & $\begin{array}{l}\text { Spanis } \\
\text { h } \\
\text { bundle } \\
(93)\end{array}$ & $\begin{array}{c}\text { Frenc } \\
\text { h } \\
\text { bundle } \\
(94)\end{array}$ & $\begin{array}{c}\text { Johns } \\
\text { Hopkin } \\
\text { s } \\
\text { bundle } \\
(95)\end{array}$ & $\begin{array}{l}\text { Level of } \\
\text { recommendati } \\
\text { on } \\
\text { (SHEA/IDSA) }\end{array}$ \\
\hline & $\begin{array}{l}\text { secretion drainage } \\
\text { ports for patients } \\
\text { expected to require > } \\
48 \text { or } 72 \text { hours of MV }\end{array}$ & & & & & & \\
\hline 9 & $\begin{array}{l}\text { Avoiding elective } \\
\text { changes of ventilator } \\
\text { circuits, humidifiers, } \\
\text { and endotracheal } \\
\text { tubes (only when } \\
\text { visibly soiled) }\end{array}$ & B & & $\mathrm{X}$ & & & High \\
\hline 10 & $\begin{array}{l}\text { Daily oral care with } \\
\text { chlorhexidine }\end{array}$ & $S$ & $X$ & X & X & & Moderate \\
\hline 11 & $\begin{array}{l}\text { Selective oral or } \\
\text { digestive } \\
\text { decontamination }\end{array}$ & $\mathrm{S}$ & & & & & $\mathrm{High}^{*}$ \\
\hline 12 & $\begin{array}{l}\text { Prophylactic } \\
\text { probiotics }\end{array}$ & $S$ & & & & & Moderate \\
\hline
\end{tabular}




\begin{tabular}{|c|c|c|c|c|c|c|c|}
\hline & Intervention & $\begin{array}{r}\text { SHE } \\
\text { A/ID } \\
\text { SA } \\
(36)\end{array}$ & $\begin{array}{c}\text { IHI } \\
\text { bundle } \\
(37,38)\end{array}$ & $\begin{array}{c}\text { Spanis } \\
\text { h } \\
\text { bundle } \\
(93)\end{array}$ & $\begin{array}{c}\text { Frenc } \\
\text { h } \\
\text { bundle } \\
(94)\end{array}$ & $\begin{array}{c}\text { Johns } \\
\text { Hopkin } \\
\text { s } \\
\text { bundle } \\
(95)\end{array}$ & $\begin{array}{c}\text { Level of } \\
\text { recommendati } \\
\text { on } \\
\text { (SHEA/IDSA) }\end{array}$ \\
\hline 13 & $\begin{array}{l}\text { Ultrathin polyurethane } \\
\text { endotracheal tube } \\
\text { cuffs }\end{array}$ & $S$ & & & & & Low \\
\hline 14 & $\begin{array}{l}\text { Automated control of } \\
\text { endotracheal tube } \\
\text { cuffs }\end{array}$ & S & & & & & Low \\
\hline 15 & $\begin{array}{l}\text { Saline instillation } \\
\text { before tracheal } \\
\text { suctioning }\end{array}$ & $S$ & & & & & Low \\
\hline 16 & $\begin{array}{l}\text { Mechanical } \\
\text { toothbrushing }\end{array}$ & S & & & & & Low \\
\hline 17 & $\begin{array}{l}\text { Peptic ulcer disease } \\
\text { prophylaxis }\end{array}$ & NR & $X$ & & & $X$ & Moderate \\
\hline 18 & $\begin{array}{l}\text { Deep venous } \\
\text { thrombosis } \\
\text { prophylaxis }\end{array}$ & & $X$ & & & $\mathrm{X}$ & N/A \\
\hline 19 & $\begin{array}{l}\text { Education and training } \\
\text { in airway management }\end{array}$ & & & $X$ & & & N/A \\
\hline
\end{tabular}




\begin{tabular}{|c|c|c|c|c|c|c|c|}
\hline & Intervention & $\begin{array}{r}\text { SHE } \\
\text { A/ID } \\
\text { SA } \\
(36)\end{array}$ & $\begin{array}{c}\text { IHI } \\
\text { bundle } \\
(37,38)\end{array}$ & $\begin{array}{c}\text { Spanis } \\
\text { h } \\
\text { bundle } \\
(93)\end{array}$ & $\begin{array}{c}\text { Frenc } \\
\text { h } \\
\text { bundle } \\
(94)\end{array}$ & $\begin{array}{c}\text { Johns } \\
\text { Hopkin } \\
\text { s } \\
\text { bundle } \\
(95)\end{array}$ & $\begin{array}{c}\text { Level of } \\
\text { recommendati } \\
\text { on } \\
\text { (SHEA/IDSA) }\end{array}$ \\
\hline 20 & $\begin{array}{l}\text { Strict hand hygiene } \\
\text { before airway } \\
\text { management and } \\
\text { glove and gown } \\
\text { compliance }\end{array}$ & & & $X$ & $X$ & & N/A \\
\hline 21 & $\begin{array}{l}\text { Control and } \\
\text { maintenance of cuff } \\
\text { pressure } \\
(\text { French: }>20 \mathrm{~cm} \\
\left.\mathrm{H}_{2} \mathrm{O}\right)\end{array}$ & & & $X$ & $\mathrm{X}$ & & N/A \\
\hline 22 & $\begin{array}{l}\text { Orogastric rather than } \\
\text { nasogastric feeding } \\
\text { tubes }\end{array}$ & & & & $X$ & & N/A \\
\hline 23 & $\begin{array}{l}\text { Avoiding gastric } \\
\text { overdistention }\end{array}$ & & & & $X$ & & N/A \\
\hline 24 & $\begin{array}{l}\text { Eliminating non- } \\
\text { essential tracheal } \\
\text { suctioning }\end{array}$ & & & & X & & N/A \\
\hline
\end{tabular}


936 B: basic practices; IDSA: Infectious Diseases Society of America; MV: mechanical ventilation;

937 N/A: not available; NR: not recommended; S: special approaches; SHEA: Society for Healthcare 938 Epidemiology of America. *Improves outcomes but not enough evidence on possible risks 939 (insufficient data on long-term impact on antimicrobial resistance).

940 


\section{Figures}

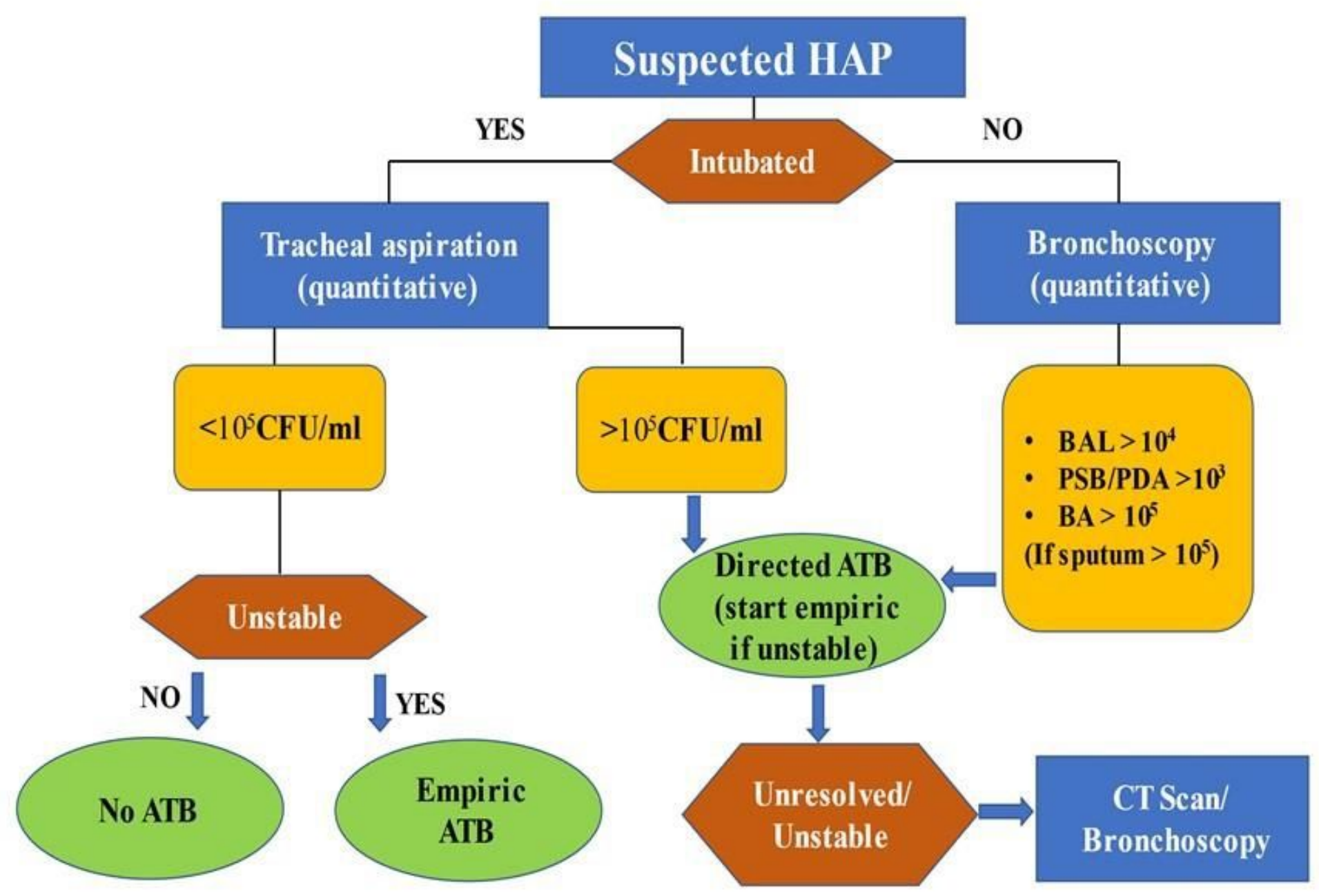

Figure 1

Algorithm for managing suspected HAP ATB: antibiotic; BA: bronchial aspirate; BAL: bronchoalveolar lavage; CFU: colony-forming unit; CT: computer tomography; HAP: hospital-acquired pneumonia; PDA: protective distal aspirate; PSB: protected specimen brushing. 


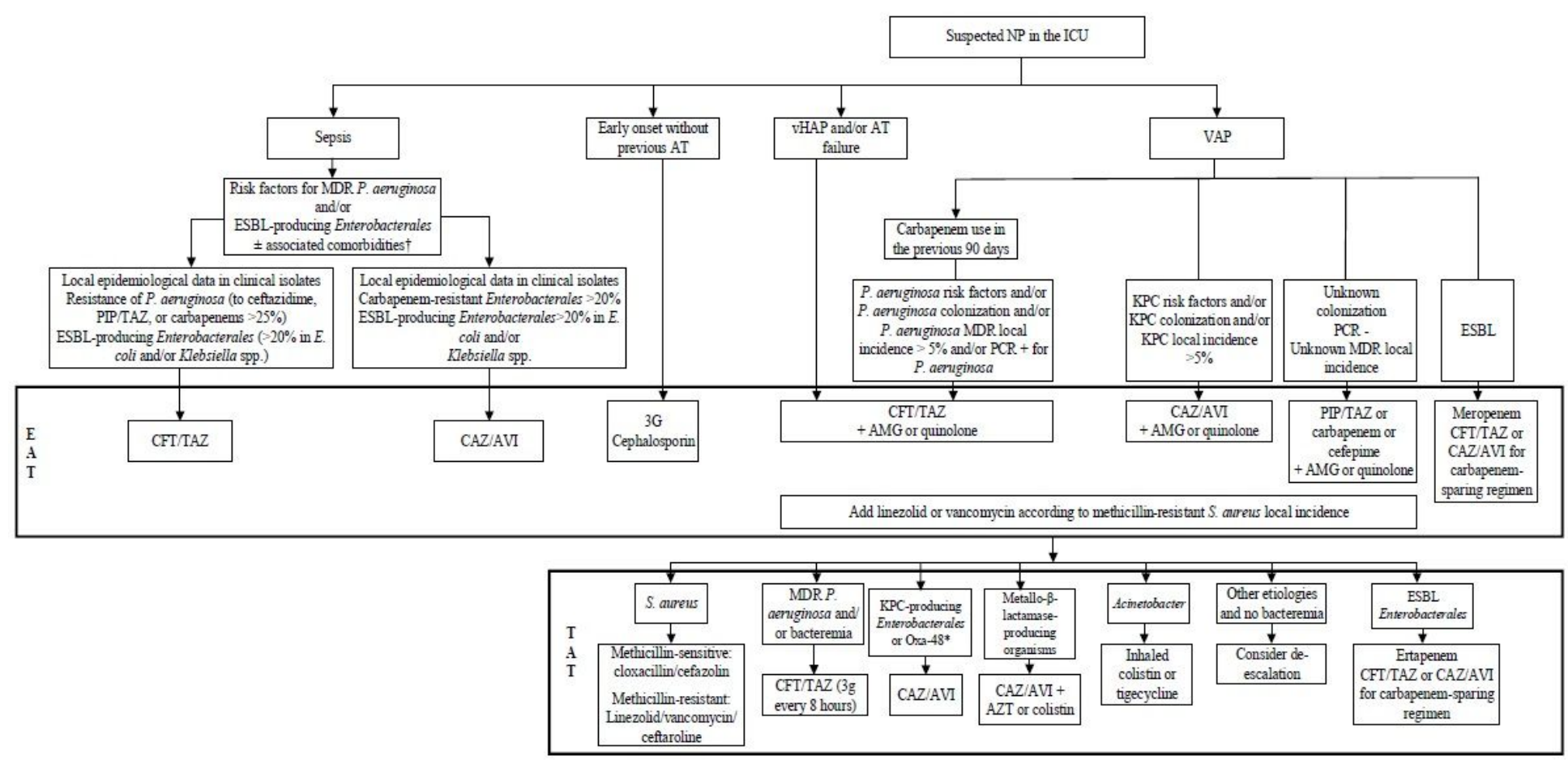

\section{Figure 2}

Treatment algorithm for VAP/HAP in ICU. AMG: aminoglycoside; AT: antimicrobial therapy; AZT: aztreonam; CAZ/AVI: ceftazidime/avibactam; CFT/TAZ: ceftolozane/tazobactam; EAT: empirical antimicrobial treatment; KPC: Klebsiella pneumoniae carbapenemase; MDR: multidrug-resistant; NP: nosocomial pneumonia; OXA-48: OXA-48 carbapenemase; PCR: polymerase chain reaction; PIP/TAZ, piperacillin/tazobactam; R: resistance; spp.: species plural; TAT: targeted antimicrobial treatment; VAP: ventilator-associated pneumonia; vHAP: ventilated hospital-acquired pneumonia. †Diabetes, COPD, moderate/severe renal/liver disease, immunosuppression/neutropenia, elderly patients, solid tumor, structural lung disease, organ transplantation, hemodialysis *If Oxa-48 susceptible to CAZ/AVI. Adapted from Montravers P. et al, 2018 (17) and Zaragoza R et al., 2020 (17,53). 